\title{
Energy and Environmental Research Emphasizing Low-Rank Coal -- Task 6.2 Joining of Advanced Structural Materials
}

\section{Topical Report}

Jan W. Nowok

John P. Hurley

March 1995

Work Performed Under Contract No.: DE-FC21-93MC30097

For

U.S. Department of Energy Office of Fossil Energy Morgantown Energy Technology Center Morgantown, West Virginia

By

University of North Dakota

Grand Forks, North Dakota

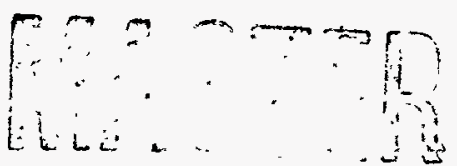




\section{Energy and Environmental Research Emphasizing Low-Rank Coal -- Task 6.2 Joining of Advanced Structural Materials}

\section{Topical Report}

Jan W. Nowok

John P. Hurley

Work Performed Under Contract No.: DE-FC21-93MC30097

For

U.S. Department of Energy

Office of Fossil Energy

Morgantown Energy Technology Center

P.O. Box 880

Morgantown, West Virginia 26507-0880

By

University of North Dakota

Energy and Environmental Research Center

P.O. Box 9018

Grand Forks, North Dakota 58202-9018 


\section{ACKNOWLEDGMENT}

This final topical report was prepared with the support of the U.S. Department of Energy (DOE), Morgantown Energy Technology Center, Cooperative Agreement No. DE-FC2193MC30097. However, any opinions, findings, conclusions, or recommendations expressed herein are those of the author(s) and do not necessarily reflect the views of the DOE.

\section{EERC DISCLAIMER}

LEGAL NOTICE This research report was prepared by the Energy \& Environmental Research Center (EERC), an agency of the University of North Dakota, as an account of work sponsored by Morgantown Energy Technology Center. Because of the research nature of the work performed, neither the EERC nor any of its employees makes any warranty, express or implied, or assumes any legal liability or responsibility for the accuracy, completeness, or usefulness of any information, apparatus, product, or process disclosed, or represents that its use would not infringe privately owned rights. Reference herein to any specific commercial product, process, or service by trade name, trademark, manufacturer, or otherwise does not necessarily constitute or imply its endorsement or recommendation by the EERC. 
LIST OF FIGURES $\ldots \ldots \ldots \ldots \ldots \ldots \ldots \ldots \ldots \ldots \ldots \ldots \ldots \ldots \ldots \ldots \ldots \ldots$

LIST OF TABLES $\ldots \ldots \ldots \ldots \ldots \ldots \ldots \ldots \ldots \ldots \ldots \ldots \ldots \ldots \ldots$ ii

1.0 INTRODUCTION $\ldots \ldots \ldots \ldots \ldots \ldots \ldots \ldots \ldots \ldots \ldots \ldots \ldots \ldots \ldots$

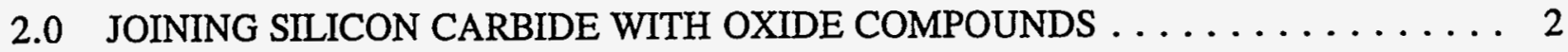

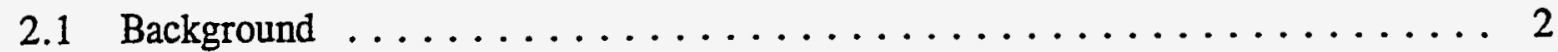

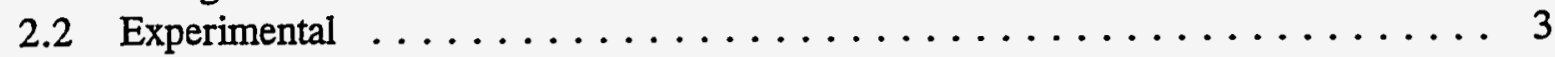

2.3 Results and Discussion ....................... 3

2.3.1 The Effect of Atmosphere on the Sintering Propensity of Mullite and Mulcoa ........................ 3

2.3.2 The Effect of Atmosphere on the Sintering Propensity and Strength Development in SiC Powder . . . . . . . . . . . . . 4

2.3.3 Strength Development in SiC-Mulcoa (70/30) Composite . . . . . . . 8

2.3.4 Mechanical Properties of Sintered Mulcoa and SiC-Mulcoa (70/30)

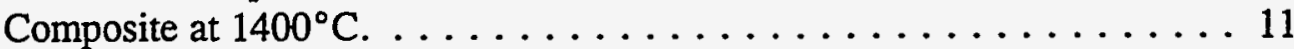

2.3.5 Joining of $\mathrm{SiC}$ Bars with Mulcoa $\ldots \ldots \ldots \ldots \ldots \ldots \ldots \ldots \ldots \ldots \ldots$

3.0 JOINING SILICON CARBIDE THROUGH JOULE HEATING $\ldots \ldots \ldots \ldots \ldots 12$

4.0 FUTURE WORK $\ldots \ldots \ldots \ldots \ldots \ldots \ldots \ldots \ldots \ldots \ldots \ldots \ldots \ldots \ldots \ldots \ldots$

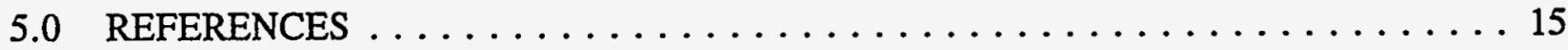




\section{LIST OF FIGURES}

1 Scheme of SiC blocks used for measurements of shear strength $\ldots \ldots \ldots \ldots \ldots$

2 Strength development in mulcoa ceramic sintered in air and water vapor $\ldots \ldots \ldots \ldots 6$

3 Strength-strain relationship in mulcoa sintered at $1500^{\circ} \mathrm{C}$ for $5 \mathrm{hr}$ in air $+30 \%$ water

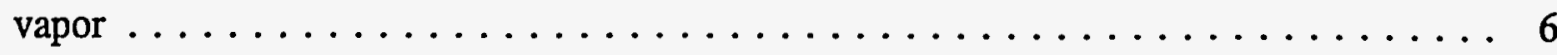

4 Strength-strain relationship in mulcoa sintered at $1500^{\circ} \mathrm{C}$ for $5 \mathrm{hr}$ in air $+30 \%$ water

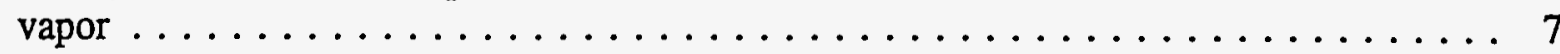

5 Microstructure of mulcoa sintered at $1500^{\circ} \mathrm{C}$ for $5 \mathrm{hr}$ in air $+30 \%$ water vapor $\ldots \ldots 7$

6 Strength development in mulcoa ceramic sintered in various atmospheres

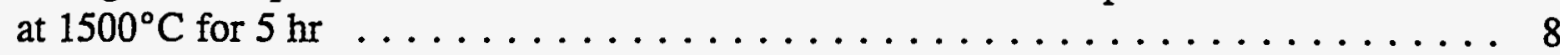

7 The effect of atmosphere on strength development in $\mathrm{SiC}$ sintered at $1500^{\circ} \mathrm{C}$ for $5 \mathrm{hr} \ldots 9$

8 The change of Gibbs free energy of formation with temperature for $\mathrm{SiC}, \mathrm{SiO}_{2}$, and $\mathrm{SiC}+\mathrm{CO}_{2} \ldots \ldots \ldots \ldots \ldots \ldots \ldots \ldots \ldots \ldots \ldots \ldots \ldots \ldots$

9 Partial pressure of oxygen (in $-\log$ scale) over $\mathrm{SiO}_{2}$ and $\mathrm{CO}_{2} \ldots \ldots \ldots$

10 Microstructure of SiC-mulcoa (70/30) composite sintered at $1500^{\circ} \mathrm{C}$ for

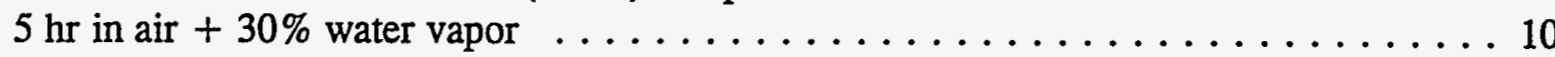

11 Stress-strain curves in mulcoa specimens sintered at $1500^{\circ} \mathrm{C}$ for $5 \mathrm{hr}$ in air +

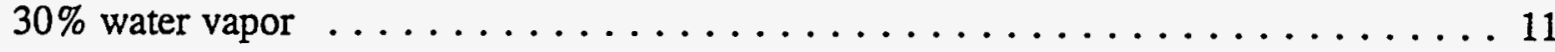

12 Stress-strain curves in $\mathrm{SiC}$-mulcoa (70/30) specimens sintered at $1500^{\circ} \mathrm{C}$ for

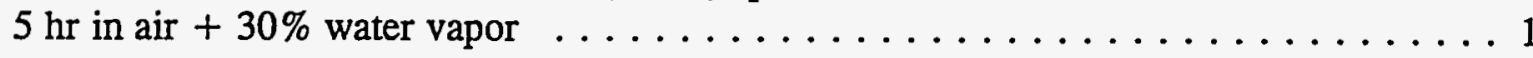

\section{LIST OF TABLES}

1 Summary of Mechanical Properties of Mulcoa, SiC, and SiC-Mulcoa Composite . . . . 5

2 Resistance of a 5-cm-long Bar of Hexoloy SA versus Temperature $\ldots \ldots \ldots \ldots$ 


\section{TASK 6.2 JOINING OF ADVANCED STRUCTURAL MATERIALS}

\subsection{INTRODUCTION}

In order to increase national energy self-sufficiency for the near future, energy systems will be required to fire low-grade fuels and use more efficient energy cycles than those available today. The steam cycle used at present is limited to a maximum steam temperature of $550^{\circ} \mathrm{C}$ and thus a conversion efficiency of $35 \%$. To boost efficiency significantly, much higher working fluid temperatures are required. This means that subsystems must operate at much higher temperatures and therefore in much more corrosive environments than those currently used. Problems of special concern are corrosion and fatigue of directly fired turbine blades, corrosion and blinding of hot-gas cleanup filters, and corrosion and failure of high-temperature heat exchangers. To prevent failure of those structures will require the use of advanced materials, particularly ceramics, for construction. To fully utilize the potential of ceramic materials in structural applications, economical and practical methods must be developed to assemble, or join, the components of the structure. Once an effective method is found, it will be possible to construct and test large ceramic structures such as high-temperature heat exchangers and other components used in combustion and energy engineering.

Silicon carbide $(\mathrm{SiC})$ is considered an attractive material for structural applications in fossil energy systems because of its corrosion and wear resistance, high thermoconductivity, and hightemperature strength. These same properties make it difficult to sinter or join $\mathrm{SiC}$. Conventional sintering techniques require applying pressure and heating to temperatures near $2000^{\circ} \mathrm{C}$, or the use of binders with lower melting temperatures, or pressureless sintering with the aid of carbon and boron to near full density about $2100^{\circ} \mathrm{C}$. $^{1}$ The sintering temperature can be reduced to $1850^{\circ}-2000^{\circ} \mathrm{C}$ if $\mathrm{SiC}$ is sintered with the addition of small quantities of $\mathrm{Al}_{2} \mathrm{O}_{3}$ and $\mathrm{Al}_{2} \mathrm{O}_{3}+$ $\mathrm{Y}_{2} \mathrm{O}_{3}$. ${ }^{2-4}$ In addition, reaction sintering has been used by mixing $\mathrm{Si}$ and $\mathrm{C}$ with $\mathrm{SiC}$ powder and heating the mixture to $1400^{\circ} \mathrm{C}$ to cause the $\mathrm{Si}$ and $\mathrm{C}$ to react and form $\mathrm{SiC}$, which bonds the aggregate together.

Work proposed for this year was to center on determining gas compositions that could be used to increase the sinterability of oxide binders and on using the binder and gas combinations to join bars of $\mathrm{SiC}$, alumina, and mullite $\left(3 \mathrm{Al}_{2} \mathrm{O} \cdot 2 \mathrm{SiO}_{2}\right)$. During the course of the year the focus was shifted to $\mathrm{SiC}$ joining alone, because it was felt that alumina and mullite are too prone to thermal shock for use in structural applications in fossil energy systems. Because of a thermal expansion mismatch between alumina and $\mathrm{SiC}$, only $\mathrm{SiC}$ and mullite were investigated as joining aides for $\mathrm{SiC}$. Therefore, the objectives of this work evolved into examining the sintering phenomena of $\mathrm{SiC}$ and mullite-derived binders at and below $1500^{\circ} \mathrm{C}$ in various atmospheres and determining which conditions are suitable to form strong joints in monolithic $\mathrm{SiC}$ structures to be used at temperatures of $1000^{\circ}-1400^{\circ} \mathrm{C}$.

Because the number of materials to be joined was reduced, the number of joining compounds was expanded and more detailed analyses of the samples were employed than originally planned. Also, some funds were shifted to preliminary investigations of the potential to use joule heating to induce reaction sintering in the joining of $\mathrm{SiC}$ monoliths. 


\section{$2.0 \cdot$ JOINING SILICON CARBIDE WITH OXIDE COMPOUNDS}

\subsection{Background}

The principal factors determining whether or not a compound will make a good $\mathrm{SiC}$ joining aid are 1) sintering temperature below that of $\mathrm{SiC}$ but above the maximum use temperature, 2) thermal expansion coefficient close to $\mathrm{SiC}, 3$ ) high creep resistance, 4) and ease of use in the chosen joining procedure. The joining technique requires the control of the $\mathrm{SiC}$-binder interface properties since it is the region of maximum distortion and deformation. ${ }^{5}$ Therefore, the interface must have properties that optimize fracture strength, toughness and corrosion resistance and minimize slow crack growth.

Generally, the strength of the SiC-binder interface is governed by the thermal expansion coefficient and elasticity mismatches, the fracture resistance of interface, the relative thickness of binder, and the flaw distributions in the $\mathrm{SiC}$ and binder layer. SiC-mullite joints offer the prospect of good high-temperature properties, since there is little difference in the coefficients of thermal expansion. However, there are still many aspects of SiC-mullite composite to be understood. One is the effect of atmosphere on sinterability and stability of the binder. Also, little information is available on high-temperature grain-boundary sliding at the $\mathrm{SiC}$-mullite interface caused by a viscous glassy phase and its effect on compressive strength.

Two major factors, the densification of mullite and the high-temperature stress-strain property of mullite binder, were considered most important in predicting the properties of a $\mathrm{SiC}$-mullite joint. The densification rate of mullite powders significantly increases in the presence of small amounts of liquid phase. Grain-boundary transport or diffusion appear to be the primary mechanism of densification. ${ }^{6.7}$ Since the melting temperature of mullite is about $1830^{\circ} \mathrm{C}$, an apparent density above $90 \%$ may be achieved by sintering powder compacts at temperatures above $1700^{\circ} \mathrm{C}$. The sintering temperature may decrease to $1500^{\circ} \mathrm{C}$ if it is performed under pressures of about $355 \mathrm{MPa}(50 \mathrm{kpsi}){ }^{8}$

Several factors were considered in determining the best conditions to stimulate the formation of mullite-SiC joints with favorable characteristics. Mechanical properties of sintered powders depend on the morphology of powder grains. Materials with columnar (or elongated) grains demonstrate higher fracture stress ${ }^{9}$ and creep resistance than those with circular grains. The formation of the columnar grains requires the presence of a liquid phase. ${ }^{1}$ The addition of a small quantity of amorphous silica should therefore lower the sintering temperature of mullite and modify the morphology of the grains. Stable mullite solid solutions should form at grain boundaries if the mullite content is $85 \% .^{11}$ If the silica content is too high, there may be some problems caused by the crystallization of cristobalite upon cooling. ${ }^{12}$ Sintering of mullite under reducing conditions accelerates volatilization of silica, which may cause the intergranular phase to be enriched in alumina. ${ }^{11}$ Also, water vapor or hydrogen in the atmosphere may create silanol groups in the silica, which may promote diffusion processes and therefore should promote sintering of SiC-mullite composites. 


\subsection{Experimental}

High purity mullite powder (melting temperature $1828 \pm 10^{\circ} \mathrm{C}$ ), a naturally occurring material known as mulcoa ( $87 \%$ mullite and $13 \%$ amorphous silica), $\mathrm{SiC}$, and mixed SiC-mulcoa $(70 / 30)$ were used in the sintering tests. All were sized below $30 \mu \mathrm{m}$. The tests were performed in air, in air and water vapor, and under reducing conditions including $\mathrm{H}_{2}=25.2 \mathrm{~mole} \%, \mathrm{CO}_{2}=$ $10.3 \mathrm{~mole} \%$, and 0-30 mole\% water vapor or $\mathrm{H}_{2} \mathrm{~S}=1 \mathrm{~mole} \%$, with $\mathrm{CO}$ making up the balance.

Ten cylindrical pellets $(1.52 \mathrm{~cm}$ in diameter and $1.90 \mathrm{~cm}$ long) formed in a hand press were sintered for $5 \mathrm{hr}$ at several temperatures, then cooled slowly in the furnace, and their average compressive strengths were measured. The strain rate was $1 \times 10^{-5} \mathrm{sec}^{-1}$. Remains of the crushed pellets were analyzed to determine their grain interface morphology and crystalline phases using scanning electron microscopy (SEM) and $x$-ray diffraction (XRD). Additionally, SiC with mulcoa powders $(70 / 30)$ were sintered with zirconium oxide $\left(\mathrm{ZrO}_{2}\right)$ additive at $1500^{\circ} \mathrm{C}$ for $5 \mathrm{hr}$ in air + $30 \%$ water vapor.

The most promising atmosphere and compound were then used to join bars of $\mathrm{SiC}$. The blocks were $6 \times 8 \times 50 \mathrm{~mm}$. After joining the shear strengths of the bonds were tested at elevated temperatures. Figure 1 shows a scheme of $\mathrm{SiC}$ blocks used for shear strength measurements.

\subsection{Results and Discussion}

\subsubsection{The Effect of Atmosphere on the Sintering Propensities of Mullite and Mulcoa}

Compressive strength development in high-purity mullite sintered at $1500^{\circ} \mathrm{C}$ for $5 \mathrm{hr}$ in air and air $+30 \%$ water vapor is listed in Table 1 . Generally, strength increases in specimens sintered in the presence of water vapor.

Figure 2 illustrates strength variation with both sintering temperature and water vapor content in air. Generally, there is a large increase of strength with water vapor content in samples sintered at $1500^{\circ} \mathrm{C}$ for $5 \mathrm{hr}$. The total porosity of sintered samples as estimated by automated image analysis of SEM backscattered electron images is constant at around $50 \%$. This suggests that the strength increase may not be caused by the increased sintering resulting from enhanced reactivity of mullite particles, but is instead due to changes in the local fracture behavior of particle-particle interfaces.

To obtain additional information on interface behavior, the strength-strain relationship was analyzed. Figures 3 and 4 show the stress-strain curves for several pellets of mulcoa sintered at $1500^{\circ} \mathrm{C}$ in air +30 vol\% water vapor. The strength-strain curves imply that some ductility is associated with particle- free interfaces. Usually, the ductile interlayer will increase joint toughness and provide transverse crack stoppers. ${ }^{13}$ The SEM analysis performed on polished sintered mulcoa showed that the intergranular phase is composed of silica and alumina, with about $7-17 \mathrm{wt} \%$ alumina and the remainder silica.

The presence of micropores in the sintered pellets modifies several physical properties, including elastic moduli, thermal conductivity and diffusivity, and dielectric constant and may also 
lead to an increase in fracture toughness. ${ }^{14}$ Cracks and microcracks in the sintered mulcoa often formed in the intergranular phase while the strength tests were performed (Figure 5). The cracks should not form because of stresses created upon cooling as a result of the anisotropy of thermal expansion coefficients of different phases, since thermal expansion coefficients of $\mathrm{SiC}$ and mullite are nearly the same.

Generally, the reducing atmosphere has a small effect on strength increase in mulcoa pellets (Figure 6, Table 1). The small increase of strength under reducing conditions may be explained by the enhanced densification resulting from the formation of nonstoichiometric phases on the surface of mullite particles which, in turn, induce surface diffusion and further the densification rate.

Mullite solid-solution can be represented by the formula $\mathrm{Al}_{4+2 \mathrm{x}} \mathrm{Si}_{2-2 \mathrm{x}} \mathrm{O}_{10-\mathrm{x}}$, where $\mathrm{x}$ is the number of oxygen atoms missing per unit cell $(0 \leq \mathrm{x} \leq 1) .^{15,16}$ The reducing atmosphere has an extremely low oxygen fugacity, which may further decrease the number of oxygen atoms in the structure and change both the sintering and strength parameters of the material.

\subsubsection{The Effect of Atmosphere on the Sintering Propensity and Strength Development in SiC Powder}

Figure 7 illustrates changes of compressive strength with sintering atmosphere and deformation temperature for $\mathrm{SiC}$ sintered at $1500^{\circ} \mathrm{C}$ for $5 \mathrm{hr}$. Water vapor and reducing atmosphere do not have a great effect on strength development in SiC. However, enhanced compressive strength is observed in samples sintered in air and deformed at room temperature and particularly at $1000^{\circ} \mathrm{C}$. The enhanced strength seems to result from the mechanical properties of

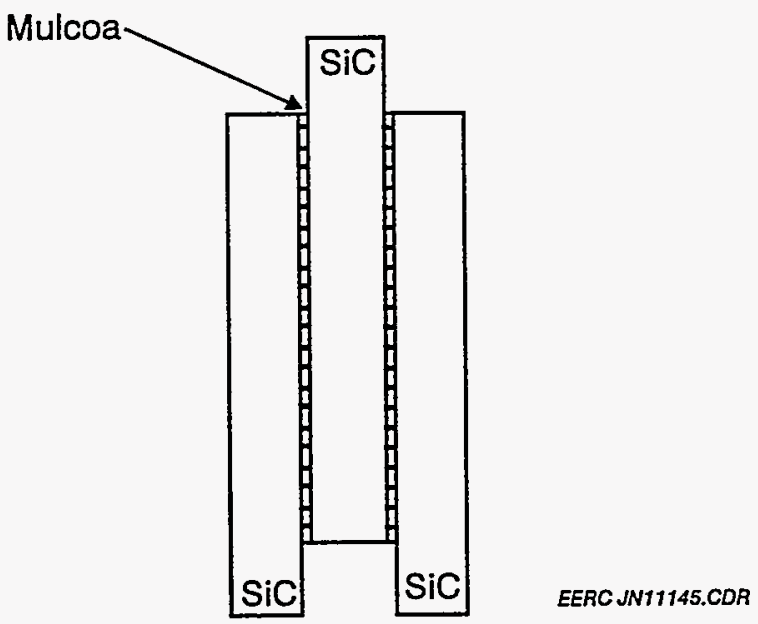

Figure 1. Scheme of SiC bars used for measurements of shear strength. 


\section{TABLE 1}

Summary of Mechanical Properties of Mulcoa, $\mathrm{SiC}$, and $\mathrm{SiC}-\mathrm{Mulcoa}$ Composite

\begin{tabular}{|c|c|c|c|c|}
\hline \multirow[b]{2}{*}{ Material } & \multicolumn{2}{|c|}{$\begin{array}{l}\text { Compressive Strength, } \\
\mathrm{MPa}\end{array}$} & \multirow[b]{2}{*}{ Porosity, \% } & \multirow[b]{2}{*}{ Atmosphere } \\
\hline & $25^{\circ} \mathrm{C}$ & $1000^{\circ} \mathrm{C}$ & & \\
\hline \multirow[t]{2}{*}{ Mullite } & 60 & 62 & $\mathrm{NA}^{1}$ & Air \\
\hline & & & NA & $\mathrm{Air}+30 \% \mathrm{H}_{2} \mathrm{O}$ \\
\hline \multirow[t]{4}{*}{ Mulcoa } & 180 & 200 & 54 & Air \\
\hline & 380 & 280 & 52 & $\mathrm{Air}+30 \% \mathrm{H}_{2} \mathrm{O}$ \\
\hline & 320 & 340 & 53 & $\begin{array}{l}\mathrm{H}_{2} / \mathrm{CO} / \mathrm{CO}_{2} / \mathrm{H}_{2} \\
\mathrm{O}\end{array}$ \\
\hline & 350 & 360 & & $\mathrm{H}_{2} / \mathrm{CO} / \mathrm{CO}_{2} / \mathrm{H}_{2} \mathrm{~S}$ \\
\hline \multirow[t]{4}{*}{$\mathrm{SiC}$} & 590 & 920 & 2.2 & Air \\
\hline & 340 & 420 & 3.5 & $\mathrm{Air}+30 \% \mathrm{H}_{2} \mathrm{O}$ \\
\hline & 290 & 310 & 4.8 & $\begin{array}{l}\mathrm{H}_{2} / \mathrm{CO} / \mathrm{CQ}_{2} / \mathrm{H}_{2} \\
\mathrm{O}\end{array}$ \\
\hline & 320 & 330 & 5.5 & $\mathrm{H}_{2} / \mathrm{CO} / \mathrm{CO}_{2} / \mathrm{H}_{2} \mathrm{~S}$ \\
\hline $\mathrm{SiC}+30 \%$ Mulcoa & 340 & 370 & 48 & $\mathrm{Air}+30 \% \mathrm{H}_{2} \mathrm{O}$ \\
\hline $\begin{array}{l}\mathrm{SiC}+30 \% \text { Mulcoa: } \mathrm{ZrO}_{2} \text {, } \\
3: 1\end{array}$ & 280 & 360 & $\mathrm{NA}$ & $\mathrm{Air}+30 \% \mathrm{H}_{2} \mathrm{O}$ \\
\hline \multirow[t]{2}{*}{$\mathrm{SiC}+30 \% \mathrm{Al}_{2} \mathrm{O}_{3}$} & 80 & 150 & NA & $\mathrm{Air}+30 \% \mathrm{H}_{2} \mathrm{O}$ \\
\hline & \multicolumn{2}{|c|}{ Shear Strength } & & \\
\hline SiC Bars/Mulcoa & 200 & 190 & NA & $\mathrm{Air}+30 \% \mathrm{H}_{2} \mathrm{O}$ \\
\hline
\end{tabular}

\footnotetext{
1 Not applicable.
}

the particle interfaces. XRD tests show the presence of cristobalite $\left(\mathrm{SiO}_{2}\right)$ in all samples sintered under both oxidizing and reducing conditions, which likely formed during oxidation of SiC. The total porosity of sintered samples was between $2.2 \%$ and $5.5 \%$. Maximum compressive strength of Coors $\mathrm{SiC}$, a well-sintered $\mathrm{SiC}$ with similar porosity $(2.3 \%)$ is around $2110 \mathrm{MPa}$ as determined by Coors. ${ }^{17}$ The much lower strength of the pellets sintered at $1500^{\circ} \mathrm{C}$ implies that they should not be used in high stress situations but that the process may be used in the creation of weaker materials such as hot-gas particle filters. 


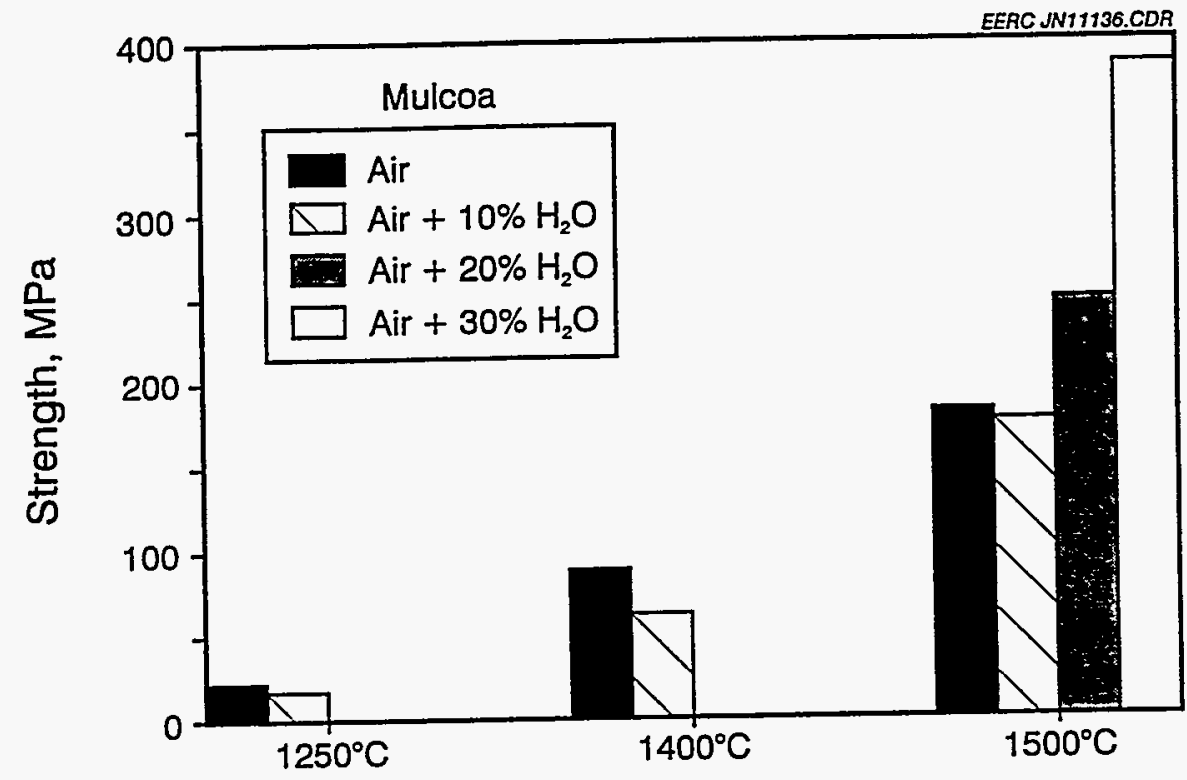

Figure 2. Strength development in mulcoa ceramic sintered in air and water vapor.

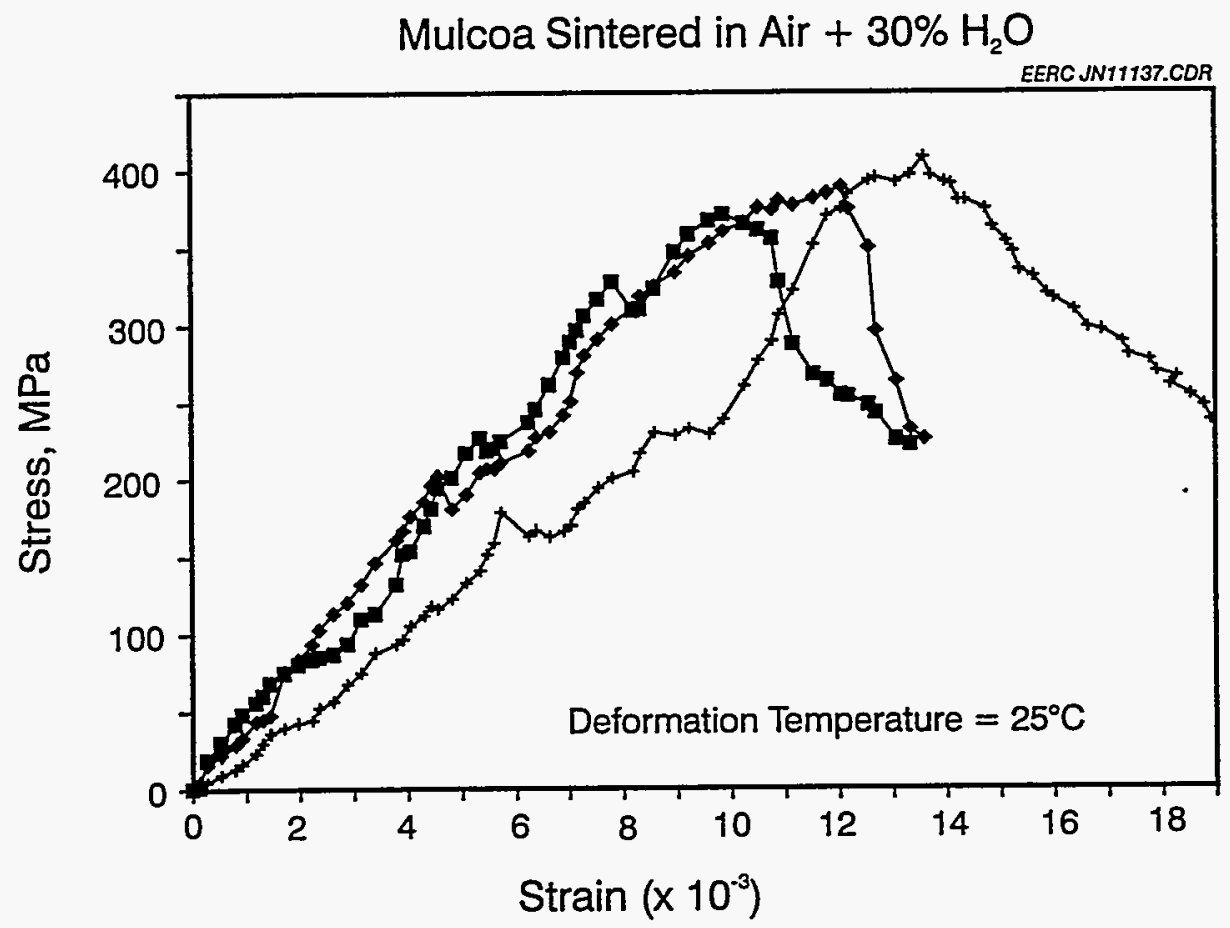

Figure 3. Strength-strain relationship in mulcoa sintered at $1500^{\circ} \mathrm{C}$ for $5 \mathrm{hr}$ in air $+30 \%$ water vapor. The three samples were deformed at room temperature. 


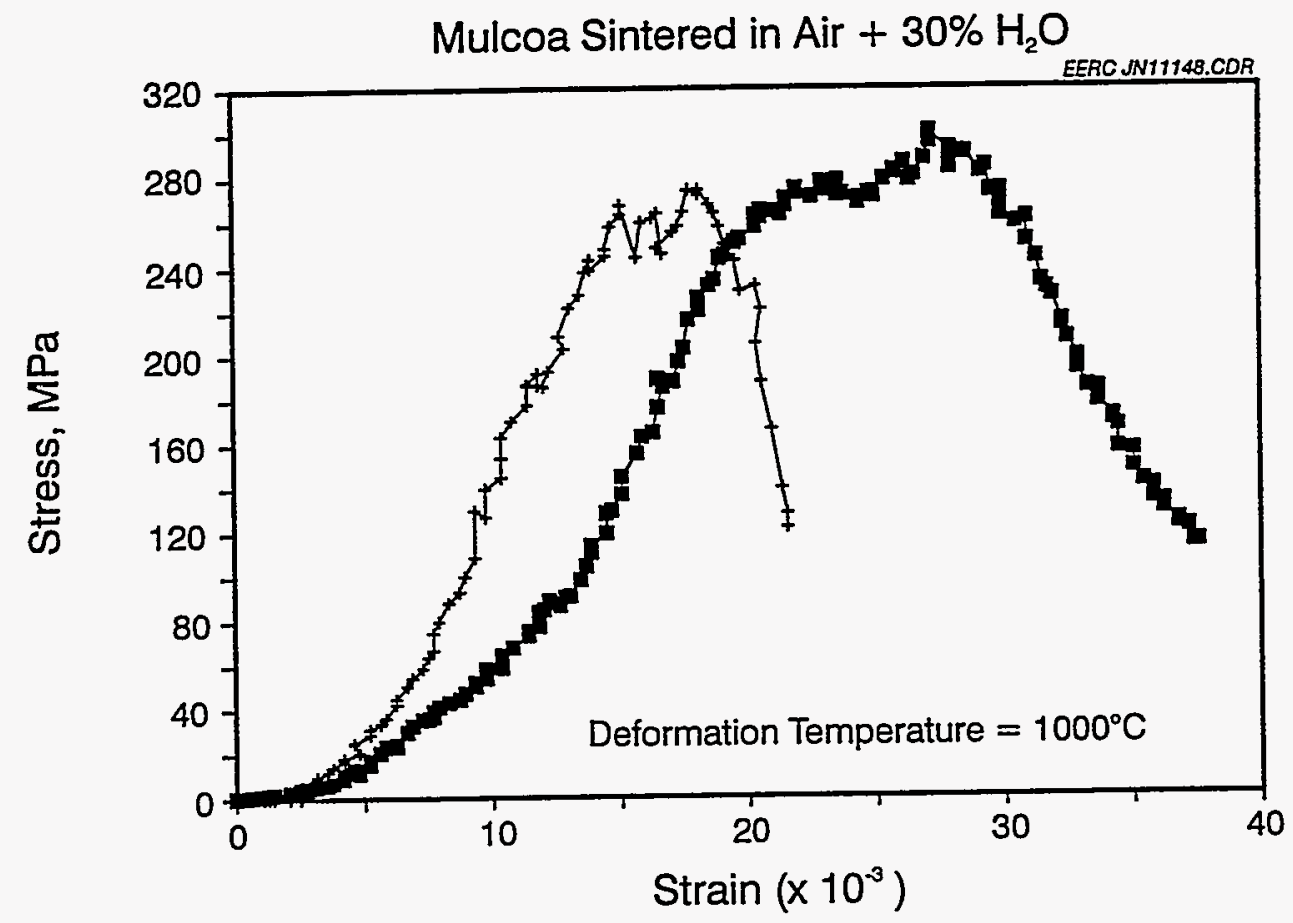

Figure 4. Strength-strain relationship in mulcoa sintered at $1500^{\circ} \mathrm{C}$ for $5 \mathrm{hr}$ in air $+30 \%$ water vapor. The two samples were deformed at $1000^{\circ} \mathrm{C}$.

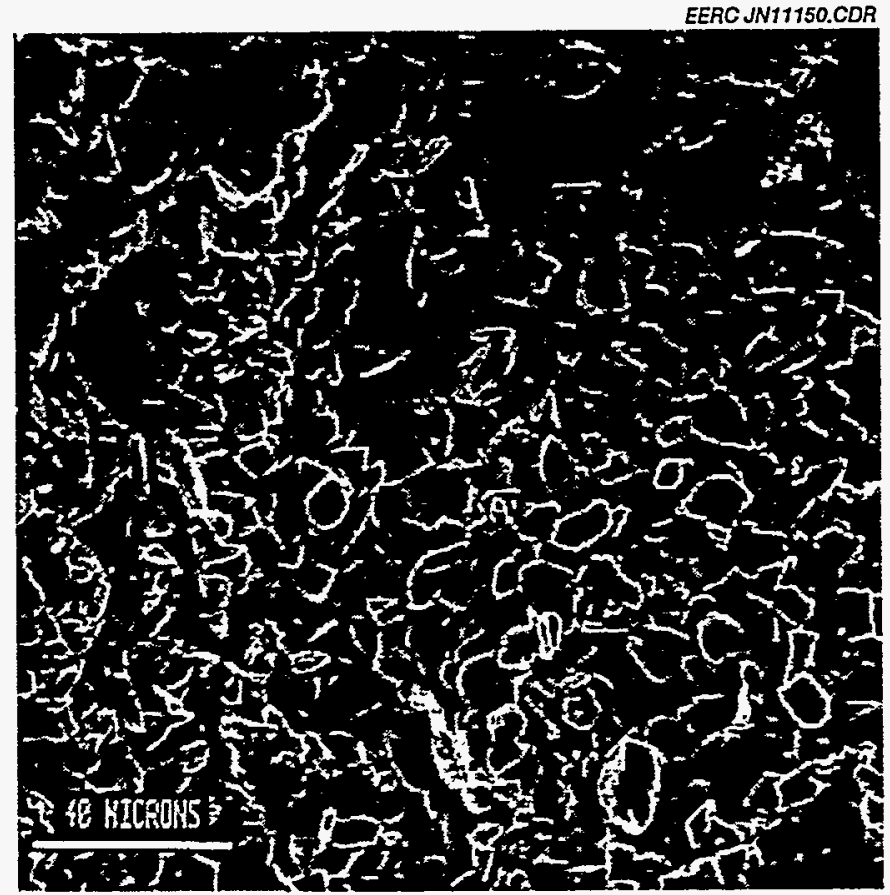

Figure 5. Microstructure of mulcoa sintered at $1500^{\circ} \mathrm{C}$ for $5 \mathrm{hr}$ in air $+30 \%$ water vapor. 


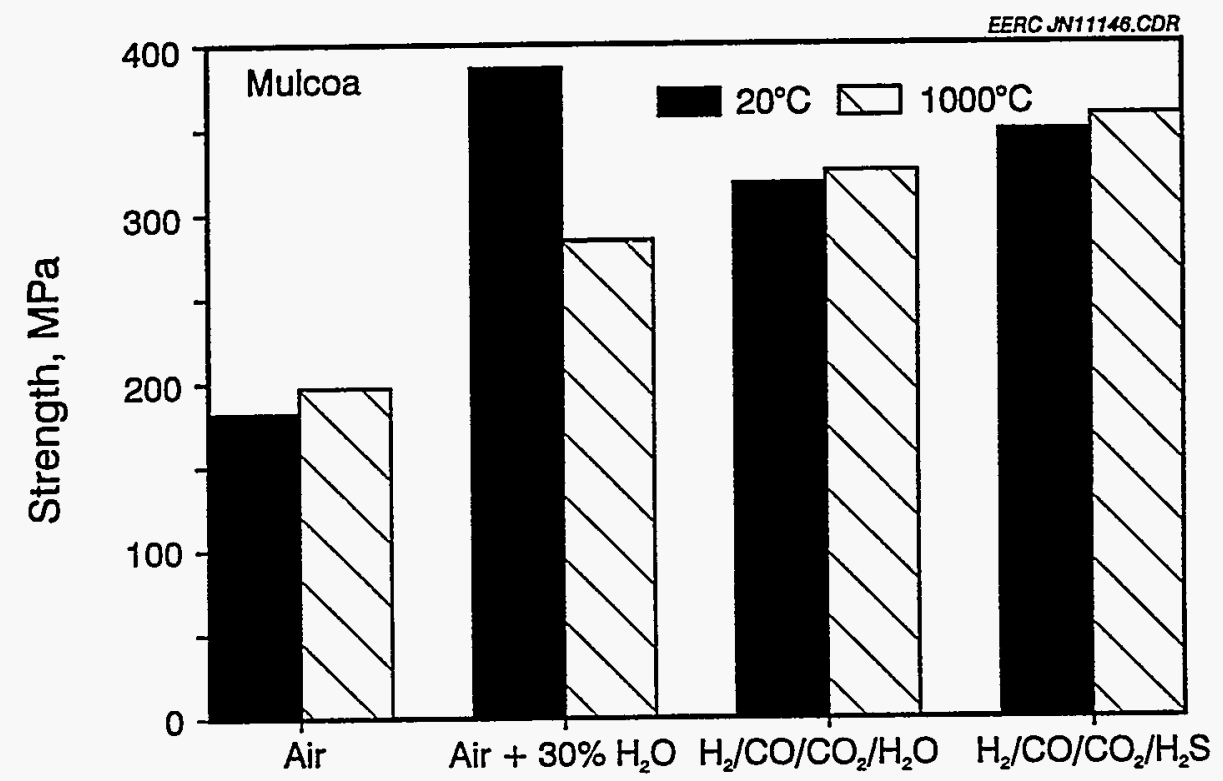

Figure 6. Strength development in mulcoa ceramic sintered in various atmospheres at $1500^{\circ} \mathrm{C}$ for $5 \mathrm{hr}$.

Figures 8 and 9 show that the change of Gibbs free energy with temperature for oxidation of $\mathrm{SiC}$ to $\mathrm{SiO}_{2}$ and higher oxygen partial pressure over $\mathrm{CO}_{2}$ than $\mathrm{SiO}_{2}$, proves that silica may be formed under reducing conditions in the presence of carbon dioxide.

\subsubsection{Strength Development in SiC-Mulcoa (70/30) Composite}

Perhaps the most striking feature of this study is that the mechanical properties of composite pellets made from a $70 / 30$ blend of $\mathrm{SiC}$ and mulcoa, sintered at $1500^{\circ} \mathrm{C}$ for $5 \mathrm{hr}$ in air $+30 \%$ water are similar to those of the pure mulcoa pellets (Table 1). This similarity provides direct information about the role of the intergranular phase on the mechanical properties of the composite. Figure 10 illustrates the microstructure of the fractured composite, which has a total porosity of about $48 \%$. The addition of a small quantity of $\mathrm{ZrO}_{2}$ into the $\mathrm{SiC}$-mulcoa composite does not change the mechanical properties of the material; however, XRD shows that an intermediate $\mathrm{ZrSiO}_{4}$ phase forms. The formation of this phase at the surface of the material may reduce alkali-based corrosion of the material in a fossil energy application. The $\mathrm{ZrSiO}_{4}$ layer would be resistant to spalling since it has a coefficient of thermal expansion very similar to that of the $\mathrm{SiC}$ and the mullite $\left(6.6 \times 10^{-6} /{ }^{\circ} \mathrm{C}, 5.3 \times 10^{-6} /{ }^{\circ} \mathrm{C}\right.$, and $5.1 \times 10^{-6} /{ }^{\circ} \mathrm{C}$, respectively). 


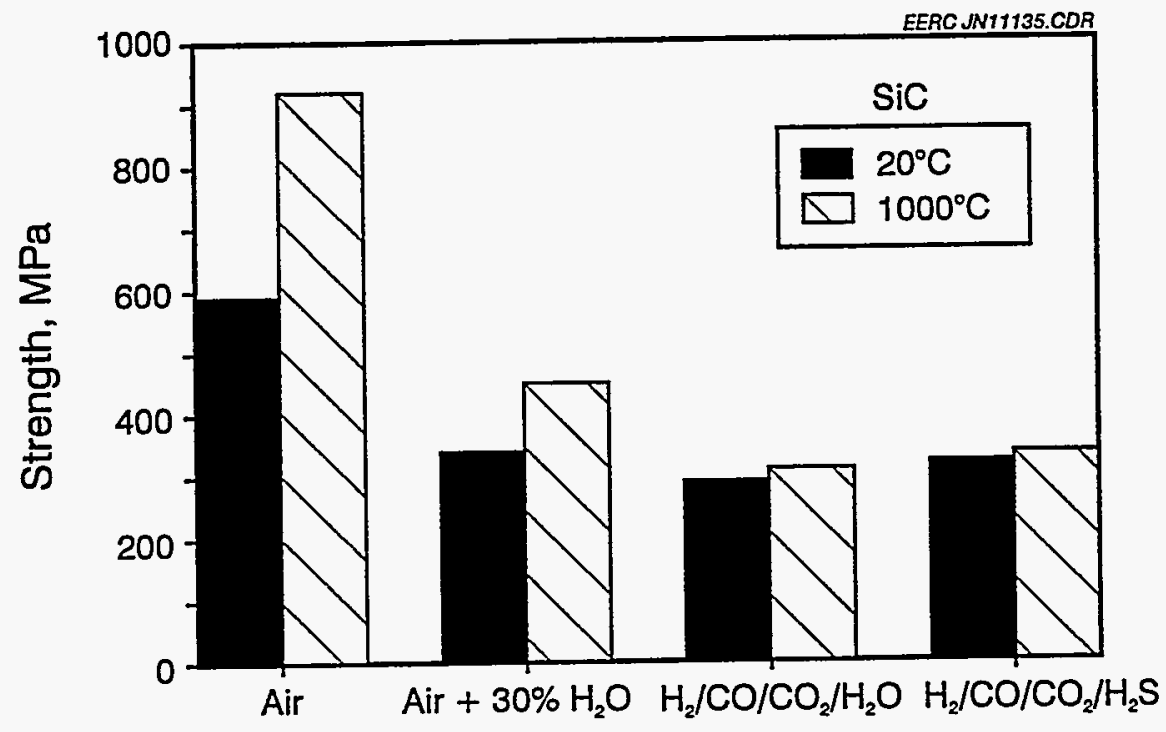

Figure 7. The effect of atmosphere on strength development in $\mathrm{SiC}$ sintered at $1500^{\circ} \mathrm{C}$ for $5 \mathrm{hr}$.

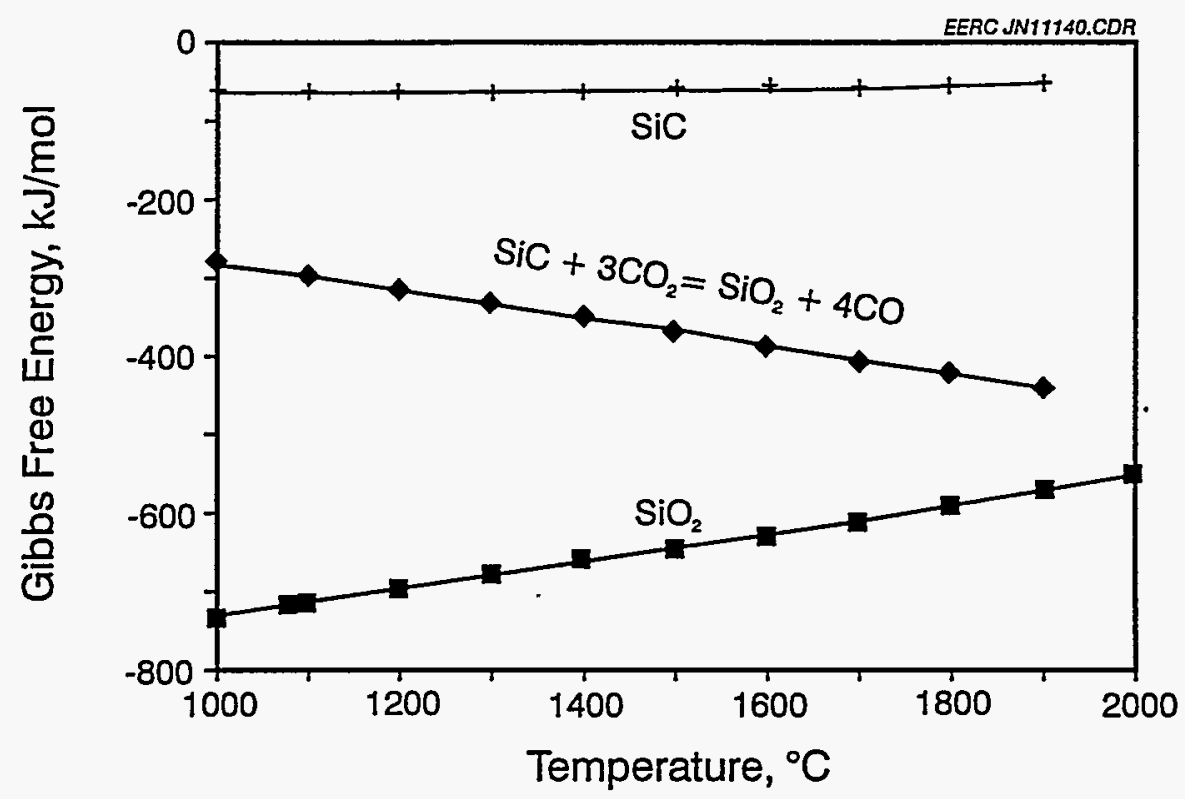

Figure 8. The change of Gibbs free energy of formation with temperature for $\mathrm{SiC}, \mathrm{SiO}_{2}$, and $\mathrm{SiC}$ $+\mathrm{CO}_{2}$. 


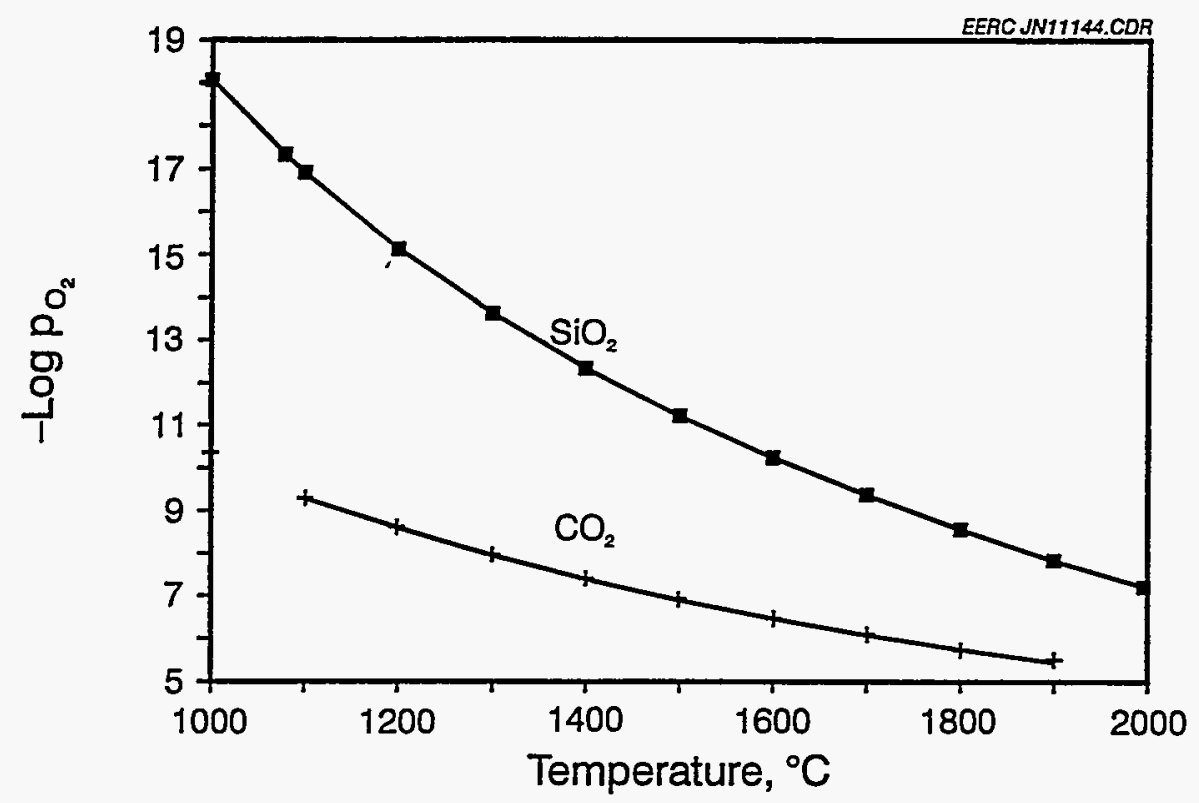

Figure 9. Partial pressure of oxygen (in - log scale) over $\mathrm{SiO}_{2}$ and $\mathrm{CO}_{2}$.

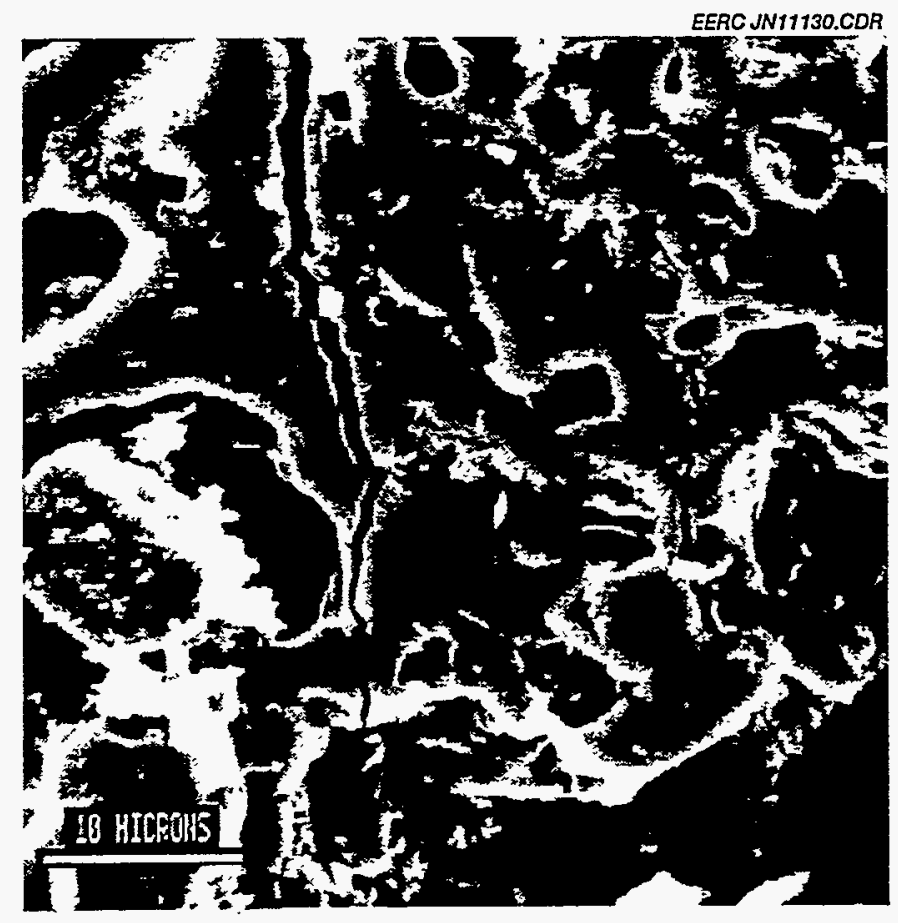

Figure 10. Microstructure of SiC-mulcoa (70/30) composite sintered at $1500^{\circ} \mathrm{C}$ for $5 \mathrm{hr}$ in air + $30 \%$ water vapor. 


\subsubsection{Mechanical Properties of Sintered Mulcoa and SiC-Mulcoa (70/30) Composite at $1400^{\circ} \mathrm{C}$}

The mechanical properties of mullite-containing composites are quite different at $1400^{\circ} \mathrm{C}$ as compared to the properties measured at room temperature or $1000^{\circ} \mathrm{C}$. Figures 11 and 12 show the relationship between applied stress and pellet strain for mulcoa and SiC-mulcoa (70/30) composite determined at $1400^{\circ} \mathrm{C}$. For mulcoa, the strength is significantly lower than that in the SiC-mulcoa composite, but shows some residual strength after fracture, as shown by the downward sloping curve after the maximum. This residual strength is important in reducing the rapidity with which a structure will fail, thereby reducing the damage caused by a failure. This residual strength or toughness is likely caused by numerous nonpropagating intergranular separations, ${ }^{18}$ and this effect is likely to be most pronounced above $1200^{\circ} \mathrm{C} .{ }^{19}$ The lower strength of the mulcoa pellets at $1400^{\circ} \mathrm{C}$ arises from the sliding of the intergranular glassy phase.

The maximum strength of the SiC-mulcoa composite measured at $1400^{\circ} \mathrm{C}$ is only slightly lower than that measured below $1000^{\circ} \mathrm{C}$. Also, there is more plasticity caused by grain-boundary sliding of the amorphous phase.

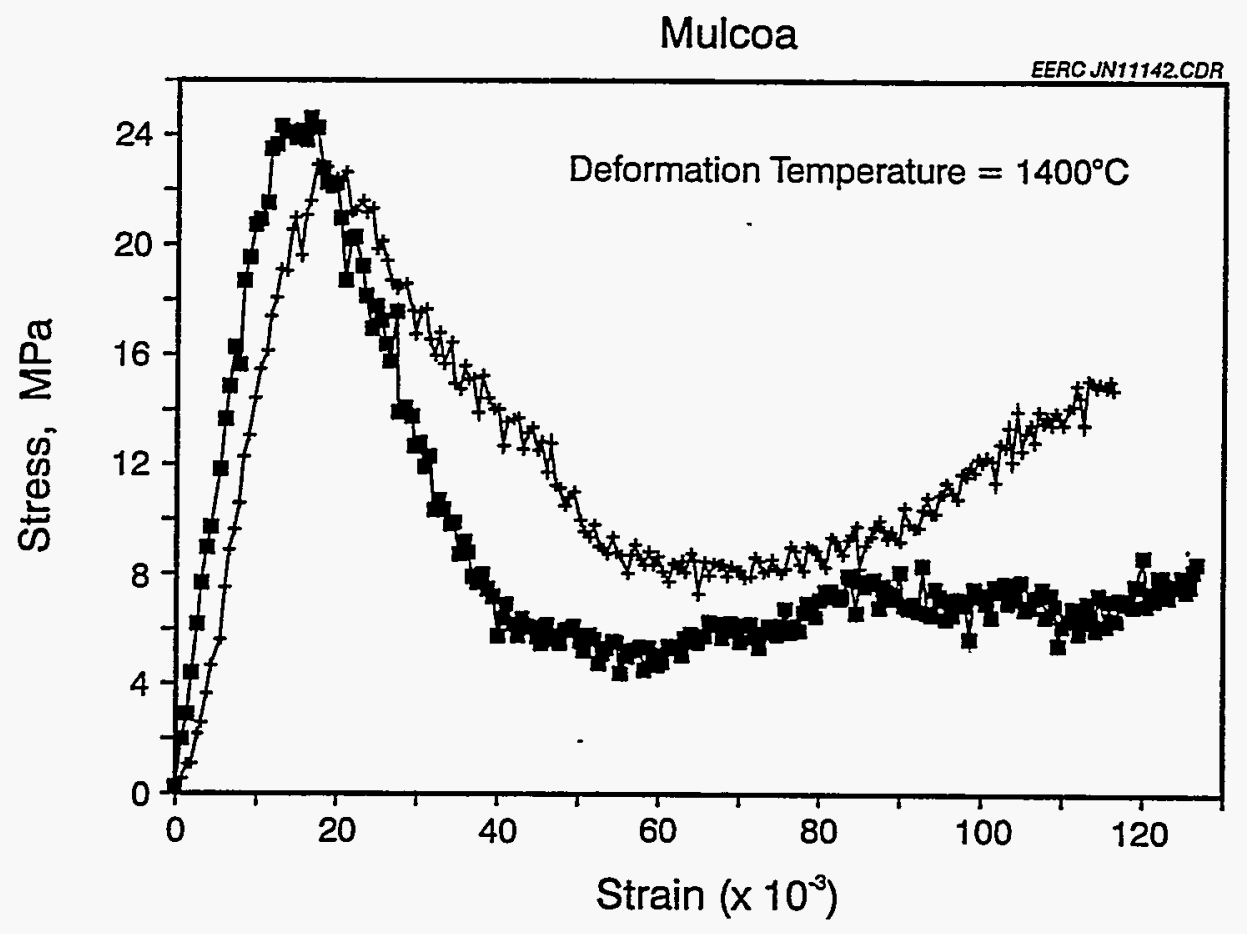

Figure 11. Stress-strain curves in mulcoa specimens sintered at $1500^{\circ} \mathrm{C}$ for $5 \mathrm{hr}$ in air $+30 \%$ water vapor. 


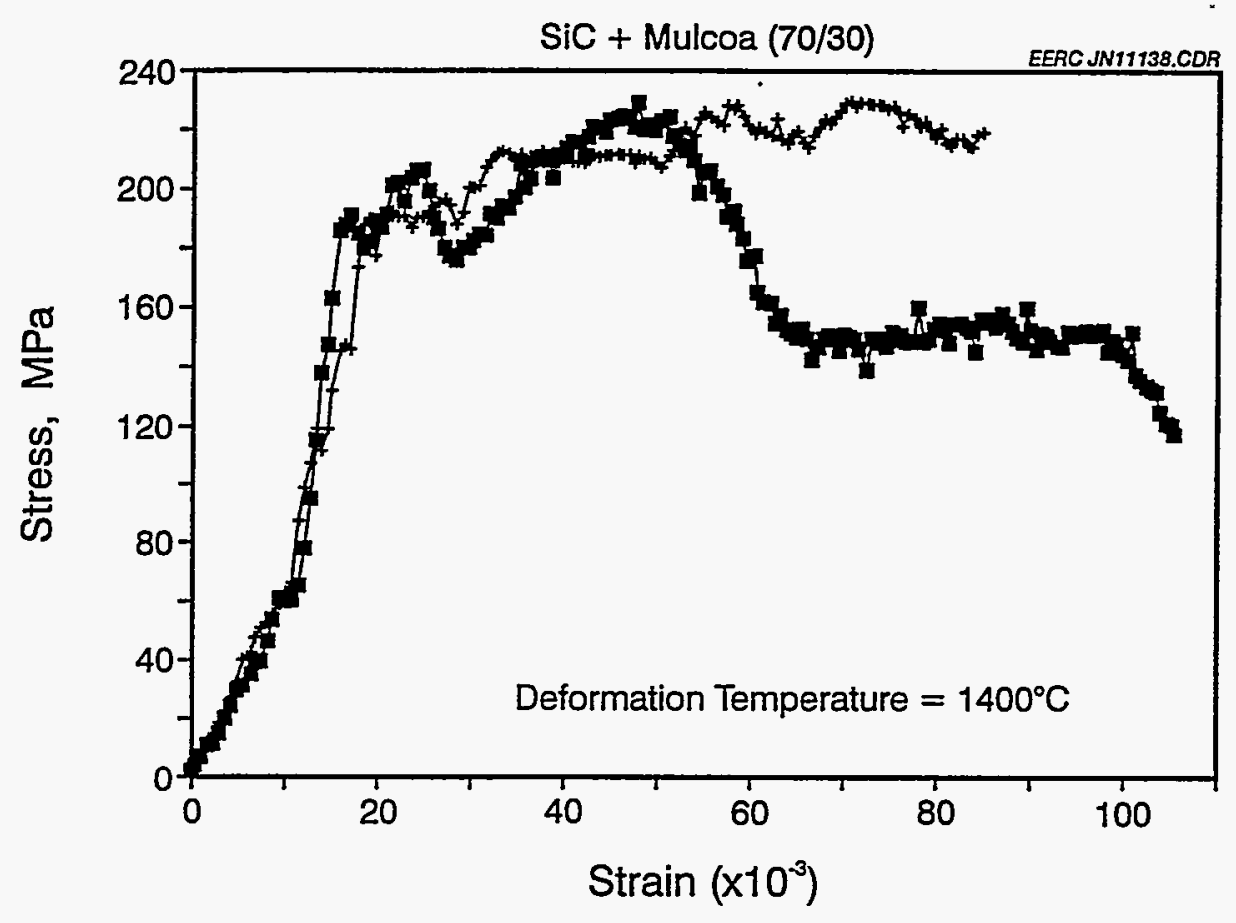

Figure 12. Stress-strain curves in SiC-mulcoa (70/30) specimens sintered at $1500^{\circ} \mathrm{C}$ for $5 \mathrm{hr}$ in air $+30 \%$ water vapor.

\subsubsection{Joining of SiC Bars with Mulcoa}

Flexure test bars $(6 \times 8 \times 50 \mathrm{~mm})$ of Hexoloy SA sintered alpha silicon carbide manufactured by the Carborundum Company were joined along the 8-mm faces with mulcoa at $1500^{\circ} \mathrm{C}$ for $5 \mathrm{hr}$ in air $+30 \%$ water vapor. The mulcoa was applied as a dry powder in a layer approximately $0.3 \mathrm{~mm}$ thick. No pressure was applied during sintering. The shear strengths of the joins measured at room temperature and at $1000^{\circ} \mathrm{C}$ are about $200 \mathrm{MPa}$ (Table 1).

\subsection{JOINING SILICON CARBIDE THROUGH JOULE HEATING}

No matter what compounds are used in joining $\mathrm{SiC}$, heat must be applied to the joint. Most often the heat comes from a secondary external source such as a furnace. Sometimes inductive heating or microwave heating is used. In all of these cases, the object needs to be surrounded by the heater. This is not a problem for smaller objects or those that are at least small in two dimensions, such as a pipe. However, for objects that are large in two dimensions, such as heat exchanger panels, such heating methods are not applicable. Therefore some preliminary work has been performed to determine whether it may be possible to heat $\mathrm{SiC}$ by passing an electric current through it. In such a scenario, electrodes would be connected to either side of the joint and an electric current passed through the material to cause resistive, or joule, heating. Silicon carbide is being focused on because it is an appropriate material with which to make a heat exchanger panels 
and because it has a lower electrical resistance than most other ceramic materials. With proper attachment of the electrodes, and because of the high thermal conductivity of SiC, heating of the joint could be made very uniform. The method has an additional advantage in that the joint is placed in an electrical field which is known to reduce the temperature necessary for reaction between ceramic precursors, a technique known as combustion synthesis. This is an especially valuable attribute in cases where the joining is accomplished by reaction sintering.

A literature search was performed for articles on ceramic-ceramic joining written between 1986 and 1993. Very few articles were found on joining SiC, none employing joule heating. A number of articles have been published recently on the joining of silicon nitride employing joule heating, primarily by $\mathrm{K}$. Okuda and others in Japan. ${ }^{20-24}$

In the so-called "electrical joining method" used by Okuda, welds are made by passing electric current through a joining compound between two ceramic monoliths. Heat is created in the joint by the resistance to the high voltage current. The current is applied through electrodes implanted all around the joint, and it is heated to the sintering temperature of the compound. However, ensuring even current flow so that sintering is uniform across the joint may not be possible if the joint is only accessible from one side, such as when an installed heat exchanger panel is being repaired. Therefore, we propose to use the ceramic itself as the electrode and pass current through the ceramic to the joint, assuring a much more even distribution of heat.

To ensure that the joint has the greatest possible high-temperature strength, $\mathrm{SiC}$ will be used as the joining material. However, $\mathrm{SiC}$ does not pressureless sinter below $2000^{\circ} \mathrm{C}$, a temperature too difficult to obtain uniformly in a large joint. In addition, unless air is excluded, the oxidation of $\mathrm{SiC}$ becomes excessive above $1600^{\circ} \mathrm{C}$. Therefore we propose to mix $\mathrm{SiC}$ powder with $\mathrm{Si}$ and $\mathrm{C}$ powders and reaction sinter the material in a manner similar to the method employed by Rabin and Moore. ${ }^{25}$ Unlike Rabin and Moore, we intend to use Si powder mixed with the $\mathrm{SiC}$ and $\mathrm{C}$ rather than infiltrating the $\mathrm{Si}$ from an exterior source as they did. Using a powder means that the regions of unreacted Si are less likely to be continuous, and so resistance to coal slag corrosion should be much higher, and strength should remain high above the melting point of the silicon $\left(1400^{\circ} \mathrm{C}\right)$, two problems associated with infiltrating the $\mathrm{Si}^{26}$ However, using powdered $\mathrm{Si}$ will cause the joining material to experience some shrinkage during sintering, so we intend to start with a more dense wafer of green material than the ceramic tape employed by Rabin and Moore.

The first step in determining the feasibility of the joining technique is to determine whether the $\mathrm{SiC}$ pieces to be joined can be used as the electrodes to carry the current. One of the biggest problems is obtaining good contact between the power source and the $\mathrm{SiC}$, because the $\mathrm{SiC}$ is so hard and usually is covered by a thin, nonconducting $\mathrm{SiO}_{2}$ layer. A number of experiments were tried, including etching the surface with hydrofluoric acid to remove the $\mathrm{SiO}_{2}$ layer, pyrolizing the surface to create a graphite layer, melting on a layer of indium metal, and rubbing on copper and aluminum metal. However, the most effective was simply coating each end of the SiC test piece with silver paint.

Table 2 shows the resistance of a $6 \times 8 \times 50-\mathrm{mm}$ bar of Hexoloy SA sintered alpha silicon carbide made by the Carborundum Company. The table shows that the resistance of the bar drops dramatically with temperature. For a given applied voltage, the current passing through the bar is determined by its resistance as given in Ohm's Law (Equation 1): 


$$
\mathrm{V}=\mathrm{IR}
$$

where $\mathrm{V}=$ voltage

$$
\begin{aligned}
& \mathrm{I}=\text { current } \\
& \mathrm{R}=\text { resistance }
\end{aligned}
$$

However, the power or heat produced varies as Equation 2:

$$
\mathrm{P}=\mathrm{I}^{2} \mathrm{R}
$$

where $\mathrm{P}=$ power

Therefore, when a constant voltage power source such as a variac is used to control the current, current runaway occurs as the bar is heated. This happens because for a fixed voltage that causes heating of the sample, the resistance drops as the temperature is raised, causing the current to increase (Equation 1). However, as the current increases, the power output increases, even though the resistance drops (Equation 2), which raises the temperature, which drops the resistance, causing a further current and temperature rise. This leads to extremely rapid temperature escalations (approximately $300^{\circ}$ to $500^{\circ} \mathrm{C} /$ second) causing thermal shock and breakage of the bars. Therefore, a current-limiting circuit must be constructed for the power source.

\subsection{FUTURE WORK}

Work and milestones are complete for calendar year 1994. In calendar year 1995, the materials work will concentrate on joining of $\mathrm{SiC}$ as described in Section 3.0 and on silicon nitride joining with SiAlON.

\section{TABLE 2}

Resistance of a 5-cm-long Bar of Hexoloy SA versus Temperature

\begin{tabular}{lc}
\hline Temperature, ${ }^{\circ} \mathrm{C}$ & Resistance, kohms \\
\hline 110 & 120 \\
125 & 25 \\
150 & 16 \\
200 & 2 \\
250 & 0.8 \\
300 & 0.28 \\
\hline
\end{tabular}




\subsection{REFERENCES}

1. Prochazka, S. "The Role of Boron and Carbon in the Sintering of Silicon Carbide," In Special Ceramics 6; Popper, P., Ed.; The British Ceramic Research Association: Stoke-on-Trent, UK, 1975; p 171.

2. Suzuki, K.; Sasaki, M. "Pressureles Sintering of Silicon Carbide," In Fundamental Structural Ceramics; Somiya, S.; Bradt, R.C., Eds.; Terra Scientific Publishing Company: Tokyo, Japan, 1987; p 75.

3. Omori, M.; Takei, H. “Pressureless Sintering of SiC,” J. Am. Ceram. Soc. 1982, 65, C-92.

4. Mulla, M.A.; Krstic, V.D. "Low-Temperature Pressureless Sintering of $\beta$-Silicon Carbide with Aluminum Oxide and Yttrium Oxide Additions," Am. Ceram. Soc. Bull. 1991, 70, 439.

5. Akselsen, O.M. "Review; Diffusion Bonding of Ceramics," J. Mater. Sci. 1992, 27, 569.

6. Sacks, M.D.; Pask, J.A. "Sintering of Mullite-Containing Materials: I, Effect of Composition," J. Am. Ceram. Soc. 1982, 65, 65.

7. Sacks, M.D.; Pask, J.A. “Sintering of Mullite-Containg Materials: II, Effect of Agglomeration," 1982, 65, 70 .

8. Mazdiyashi, K.S.; Brown, L. M. "Synthesis and Mechanical Properties of Stoichiometric Aluminum Silicate (Mullite)," J. Am. Ceram. Soc. 1972, 55, 548.

9. Lange, F. F. "Relation Between Strength, Fracture Energy, and Microstructure of HotPressed $\mathrm{Si}_{3} \mathrm{~N}_{4}$," J. Am. Ceram. Soc. 1973, 56, 518 .

10. Wilcox, B. A.; Clauer, A. H. "Role of Grain Size and Shape in Strengthening of DisperionHarded Nickel Alloys," Acta Metall. 1972, $20,743$.

11. Davis, R. F.; Pask, J. A. "Mullite," In High Temperature Oxides, Alper, A. M., Ed; Academic Press, 1971; part IV, p 37.

12. Beall, G. H. "Refractory Glass-Ceramics," In High Temperature Oxides; Alper, A. M.; Ed; Academic Press, 1971; Part IV, p 15.

13. Partridge, P. G.; Dunford, D. V. "The Role of Interlayers in Diffusion Bonded Joints in Metal-Matrix Composites," J. Mater. Sci. 1991, 26, 2255.

14. Singh, J. P.; Hasselman, D. P. H.; Su, W. M.; Rubin, J. A.; Palicka, R. "Observation on the Nature of Micro-Cracking in Brittle Composites,” J. Mater. Sci. 1981, 16, 141.

15. Cameron, W. E. "Mullite: A Substituted Alumina," Amer. Mineral. 1977, 62, 747. 
16. Schneider, H.; Eberhard, E. “Thermal Expansion of Mullite," J. Am. Ceram. Soc. 1990, 73, 2073.

17. Coors/ACI, internal information.

18. Dokkop, P. C.; Pask, J. A.; Maziyasni, K. S. "Thigh-Temperature Mechanical Properties of Mullite Under Compression," J. Am. Ceram. Soc. 1977, 60, 150.

19. Mah, T. 1.; Mazdiyasni, K. S. "Mechanical Properties of Mullite," J. Am. Ceram. Soc. 1983, $66,699$.

20. Kohyama, M. et al. "Electric Discharge Welding of Ceramics," Yogyo Kyokaishi 1986, 94 , 1197-200.

21. Okuda, K. et al. "Electrical Joining Method of Ceramics," In Proceedings of the Fall Meeting of the Ceramic Society of Japan; Ceramic Society of Japan, Tokyo, Japan, 1988, pp 467-68.

22. Ebata, Y. et al. "Electrical Joining of Silicon Nitride Ceramics, " J. Ceram. Soc. Japan 1989, 97, 88-90.

23. Moore, T.J. "Feasibility Study of the Welding of SiC," J. Am. Ceram. Soc. 1985, 68 (6), C151-C153.

24. Okuda, K.; Takai, H.; Nishi, T. "Electrical Joining of Silicon Nitride Ceramics," J. Am. Ceram. Soc. 1993, $76(6), 1459-65$.

25. Rabin, B.H.; Moore, G.A. "Joining of SiC Using Reaction Bonding Methods," In Structural Ceramics Joining II; The American Ceramic Society, 1993; p 291.

26. Strobel, T.M.; Hurley, J.P.; Breder, K.; Holowczak, J.E. "Coal Slag Corrosion and Strength Degradation of Siliconized Silicon Carbide," In Ceramic Engineering and Science, Proceedings of the 19th Annual Conference on Composites and Advanced Structural Materials; Cocoa Beach, 1995, in print. 